Nathan Myers ${ }^{1}$

\title{
Coordination, Communication, and Clade X: Challenges and Lessons Learned from Health Emergency Exercise After-Action Reports and How They Can Help Guide Future Efforts to Improve Information Sharing
}

\author{
${ }^{1}$ Associate Professor, Department of Political Science, Indiana State University, Terre Haute, IN, USA, E-mail: \\ nathan.myers@indstate.edu
}

\begin{abstract}
:
Clade $\mathrm{X}$ is only the latest in a series of high profile health emergency preparedness exercises intended to better equip government officials and responders at different levels of government and in different sectors for the challenges they are likely to face during a pandemic or bioterrorism event. A key issue in regard to emergency preparedness response is information sharing. This study examines previous literature on the importance of information sharing to emergency response, particularly in regard to public health emergencies. A content and correspondence analysis of data collected from exercise after-action reports is then conducted to examine the prominence of information sharing as a theme in those reports. The relationship between information sharing and other themes is also considered. Specific passages regarding information sharing are examined to consider how the theme is discussed in the context of the report. The findings of the analyses above are then compared to a recent tabletop exercise conducted by the Nuclear Threat Initiative regarding a biological attack. The comparison of this recent exercise to previous exercises is used to highlight key policy considerations. Recommendations are provided regarding how policy makers could help to address these considerations prior to a real world emergency. While technology is consistently evolving to improve the means by which we can share information, issues of coordination, including between the public health and health care sectors, continue to remain an obstacle.
\end{abstract}

Keywords: after action reports, bioterrorism preparedness, information sharing, pandemic preparedness, tabletop exercise

DOI: $10.1515 /$ jhsem-2018-0048

\section{Introduction}

\section{Research Problem}

There are many threats that test national and international security every day, and due to finite resources priorities must be set as to which will be given greater attention. Preparedness for threats posed by infectious diseases is an issue that has waxed and waned in terms of public salience. In the aftermath of the 9/11 attacks and the anthrax mailings soon after, disease preparedness took on great importance. Other subsequent health emergencies, such as H1N1 influenza, Ebola, and Zika, have propelled it back on to the agenda of policy makers, but it has a tendency to fade from mind after the storm has passed. Public health and medical officials are nevertheless required to exercise capabilities to address such threats on a regular basis, particularly in the US, where the Centers for Medicare and Medicaid Services implemented a new emergency preparedness rule (Emergency Preparedness Rule 2017). One key capability is to rapidly and accurately share information.

The need to improve performance in this area was recognized before the $9 / 11$ attacks through the first TOPOFF exercise in 2000. Information sharing continued to be emphasized and tested through subsequent exercises in that series, as well as other exercises as recently as 2019. Such exercises are intended to force policymakers to confront the stark realities and choices presented by a pandemic emergency and come up with options for addressing the situation, identify gaps preventing action, as well as craft options for reform. 
In this paper, we will begin by examining the academic literature on information sharing as it pertains to public health emergency preparedness and response. Then notes from the recent Clade $\mathrm{X}$ exercise as well as coded segments from after-action reports from two other tabletop emergency preparedness exercises (Dark Winter, Atlantic Storm), one functional exercise (Global Mercury), and four full-scale exercises (TOPOFF 1, 2, 3 , and 4) will be examined using correspondence analysis to investigate the relationship between information sharing and other themes. After the dominant themes from the exercises have been determined, the paper will examine key passages from the emergency preparedness exercises to better understand the context in which information sharing was an issue in these exercises. The study will close with a discussion of a 2019 tabletop exercise among international organizations to consider areas that remain an issue and improvements that have been made.

The research questions underlying this study are: (1) What is the relationship between information sharing and other key capabilities in an emergency response, based on the after-action reports from exercises? (2) What challenges are created by intergovernmental and interagency relationships during an emergency? (3) How can these challenges be addressed through the use of exercises or other policy approaches?

\section{Pandemic Exercises and Response}

Among the approaches to institutionalizing preparedness in the different sectors of American society are different forms of exercises. Utilizing this approach is usually the responsibility of a jurisdiction's bioterrorism or emergency preparedness coordinator (Lurie, Wasserman, and Nelson 2006).

One of the most commonly used forms of exercise is the tabletop exercise. Dausey, Buehler, and Lurie (2007) note that FEMA defines a tabletop exercise as "a facilitated group analysis of an emergency situation" (2). Alternatively, Peterson and Perry (1999) define a tabletop exercise as a guided walk-through of the plan involving a simulated event (usually described to participants in a narrative). Objectives tend to be general and actions involved are "action intentions" (244).

Goals of exercises include building relationships, training staff, and evaluating preparedness. They can be used for identifying gaps and variations in preparedness and making recommendations regarding improving preparedness. Increased use of tabletop exercises by health departments has promoted more knowledge sharing about lessons learned, which can help to identify shared challenges or allow for promotion of better strategies for exercise design and management (Dausey, Buehler, and Lurie 2007).

Common elements of tabletop exercises include the use of hypothetical scenarios, group discussion, and some level of collective decision making. The exercises serve to test coordination and communication among, for example, health departments, as well as between health departments and partnering agencies and organizations. Some scenarios involve time frames of days or weeks, requiring more coordination between the local and state level and more consideration of issues of medical surge. Exercises typically conclude with a "hotwash," where overall performance as well as strengths and weaknesses are assessed. Participants are also often asked to relate the exercise to prior experiences in the field (Dausey, Buehler, and Lurie 2007).

Most jurisdictions complete after-action reports on completed exercises, but evaluation of performance in AAR's frequently lacks reference to clear standards and measures, which impedes improvement efforts. The results from exercises are often not widely communicated. Few jurisdictions can point to specific instances where identification of gaps led to corrective action. Systematic quality improvement in regard to preparedness was found to be rare (Lurie, Wasserman, and Nelson 2006). Skryabina et al. (2017) also found through a scoping literature review that there was little evidence that lessons learned from preparedness exercises have been properly addressed. Some states have required regular preparedness exercises as a condition of receiving federal funds. One state tracked gaps identified in after-action reports and required corrective action as part of the jurisdiction's contract with the state (Lurie, Wasserman, and Nelson 2006). Regular participation in tabletop exercises in particular have been found to result in more in-depth discussion and focus on system-wide issues (Skryabina et al. 2017).

Organizations can also participate in functional and full-scale exercises. A functional exercise, as defined in the WHO Exercise Simulation Manual (2017), is a "fully simulated, interactive exercise that tests the capability of an organization to respond to a simulated event" and includes a focus on the coordination of "an organization's policies, procedures, roles, and responsibilities before, during, or after a simulated event" (4-5). A full-scale exercise is meant to test all or a major portion of functions. These are resource intensive, requiring a full staff of evaluators and controllers, actors, and props. Participants must execute their part of the plan in the field in real time (Peterson and Perry 1999). Verni (2012) cites the successful evacuation of 947 patients from a hospital using a plan refined through full-scale exercises to support the value of engaging in preparedness exercises (as cited in Skryabina et al. 2017). 
The exercises serve to test coordination and communication among, for example, health departments as well as between health departments and partnering agencies and organizations (Dausey, Buehler, and Lurie 2007). Zylberman (2010), in his critique of the use of worst case scenarios in emergency preparedness exercises, expressed concern that nations focusing on health preparedness as a security issue can hinder international efforts to promote improved human security in regard to controlling infectious disease.

\section{Information Sharing, Emergency Communications, and the Public Health System}

Communications and information management and sharing are key components of the US' National Incident Management System (NIMS). NIMS promotes interoperability and compatibility of first responder systems, as well as information security, authenticity, and timely delivery of data (Walker 2011). According to the 2014 National Emergency Communications Plan, "ensuring operable and interoperable communications and realtime information sharing among responders during all threats and hazards is paramount to the safety and security of all Americans" (National Emergency Communications Plan 2014, i).

Both exercises and real world responses illustrate the importance of public information systems for communicating timely and accurate information to the public before, during, and after an emergency. While the 2008 National Emergency Communications Plan noted the need for coordinated, interoperable communication between responders in the event of a terrorist attack or natural disaster, in the context of the plan public health was often regarded as a secondary concern of the catastrophe. For example, public health was referenced as a system that could be negatively impacted by an event or attack, whereas elsewhere public health information is characterized as an aspect of situational awareness. There was a shift toward the whole community approach regarding emergency preparedness that the US federal government began adopting in 2011. This included an effort to better coordinate federal, state, and local activities, including the promotion of regional structures to facilitate multi-state information sharing (National Emergency Communications Plan 2008, 2014). According to the 2014 National Emergency Communications Plan, public health and health care organizations can participate in surveillance and sharing information through social media and should be included as part of an interoperable communications system as well as the revision of standard operation procedures for that system. Public health and health care organizations should have representatives on state governance boards overseeing progress toward interoperable systems. The full continuum of public safety agencies, including public health and medical, should be incorporated into training and preparedness exercises, something that was codified in the 2016 CMS emergency preparedness regulations (No Author, "Emergency Preparedness Rule" 2017). This is seen as particularly important at the local level, as local responders will be first to confront the effects of an emergency (National Emergency Communications Plan 2014).

Effective communication is determined by the message, but also the communication system or tool, the delivery format, and the system's robustness. In regard to health-related information, two types of messages are health alerts (information of the highest importance that requires immediate attention and action) and health advisories (key information for a specific situation that may not require immediate action). Delivery of healthrelated emergency communication should include both electronic and non-electronic means. An electronic means is the Health Alert Network (HAN), through which information about infectious disease outbreaks and public health implications of natural disasters is transmitted (Revere et al. 2011).

In situations involving a public health component, sharing of information between health care providers and public health personnel must be bi-directional. Survey results indicate deficiencies in information being transmitted from public health departments to physicians (based on the H1N1 response). Physicians can choose to receive information directly from the CDC through the Clinician Outreach Communication Activity, which could reduce the potential for redundant or conflicting information. Multiple communication systems may increase, not decrease, communication problems, including the problem of alert overload (Revere et al. 2011).

The Incident Command System, which has become the standard in the field of emergency management, is intended to avoid problems such as alert overload. When ICS is activated, positions within the Incident Command System include the Liaison Officer, who serves as the point of contact for assisting agency representatives, and the Public Information Officer, who prepares accurate and complete information and releases the information about the incident to the news media and other appropriate agencies. The PIO is also responsible for maintaining activity and unit logs as needed. The Incident Commander provides instruction on the release of approved information to the news media and posting and updating news releases, as well as facilitating tours and photo opportunities in an area where the safety of the press can be guaranteed. When necessary, a joint information center can be established, which requires workspace, materials, telephones, and staffing to meet the responsibility of preparing an initial information summary as soon as possible (Walker 2011).

According to NIMS, jurisdictions need to provide technology and application training for users. It is recommended that tabletop exercises be used to reinforce training and identify response gaps and that all who 
would be involved with using or deploying the communication solution be involved in a full functional exercise (Walker 2011).

\section{Importance of Information Sharing in Pandemic Response}

One of the many lasting legacies of the 9/11 attacks and anthrax mailings in 2001 is how it highlighted the need for better preparedness, coordination, communication, and countermeasures development in the US (Annas 2002). The 2001 response to the anthrax attacks relied heavily on the use of electronic communications systems; however, the effectiveness of message coverage suffered due to a lack of contact information, old email addresses, and incomplete registries (Hills et al. 2011). Over the last decade, actors involved in public health emergency preparedness have developed and revised emergency operations plans, acquired new technology for information sharing, hired additional personnel, and enhanced training programs. However, it is often unclear how effective these efforts are due to the rarity of public health emergency events (Biddinger et al. 2010).

Limited communications, especially when it comes to sharing information about health risks among agencies; difficulty communicating health risks, under conditions of uncertainty, to the public; and insufficient use of the Health Alert Network also represented barriers (Biddinger et al. 2010). Preparedness planning has forged better communication and collaborative partnerships. Integrating preparedness with other key public health functions resulted in better performance during exercises. Less-integrated departments fared more poorly on tabletop exercises or during real events (Lurie, Wasserman, and Nelson 2006).

Information needs to be able to flow freely between organizations and needs to be easily understood by response actors regardless of discipline (Jackson et al. 2006). During an emergency response, the need for coordination and integration between responders at different levels will be more intense, requiring more formalization and documentation. The public must be given enough information to protect themselves, but responders must take care not to induce panic. Coordinated communication is difficult when multiple agencies from multiple levels of government are involved. Responders must take care regarding the timing of information, as releasing information can have dire economic and social consequences, particularly when it comes to the agricultural sector and zoonotic diseases (Jackson et al. 2006).

Large-scale, coordinated team efforts faces challenges including team cognition, shared mental models, and shared situational awareness (Endsley and Garland 2000; Militello et al. 2007; Salas and Fiore 2004). This can be mitigated to some degree through ties with the private sector (Jackson et al. 2006), such as ties between government and industry to share intelligence on agroterrorism (Lubroth 2006). However, a lot of departments who engaged in exercises had a lot of uncertainty about how to communicate with vulnerable or underserved populations, and many did not have relationships with community leaders or organizations through which they could channel information (Jackson et al. 2006).

Bharosa et al. (2009), in their study of exercises conducted in the Netherlands, noted the important role played by information managers in those exercises. Based on their observations in emergency operating centers during exercises, the information manager took notes electronically and clustered the information from a multi-agency decision making session into an electronic form, which can be stored, edited, disseminated, and communicated. Managers are expected to maintain information quality for relief workers, with this role often played by a police official. This position should act as a boundary spanner and fill the gap between information demand and information supply.

However, this approach was not without flaws. Managers and plotters are not well-institutionalized in the decision-making process, often seen as passive black boxes. With information managers responsible for creating new situation reports and updating old reports, sometimes older information was not updated in a timely manner. After a while respondents stopped looking at the displays because they knew it would not be updated information. This hampered situational awareness (Bharosa et al. 2009). Militello et al. (2007) recommended that the layout of the EOC needs to facilitate movement and communication. Shared displays with updated information are powerful tools. Mechanisms for passive and deliberate communications should be provided (Militello et al. 2007).

Another challenge related to information sharing noted above was separating good information from bad information. Bharosa, Lee, and Janssen (2010) noted that poor information sharing can lead to inappropriate allocation of first responder resources, counter-productive ordering of sequential processes, and delayed evacuations. All of these can escalate a crisis and increase casualties. Emergency management staff are concerned with becoming distracted by irrelevant or non-critical information. In a scoping review of AAR's, Savoia, Agboola, and Biddinger (2012) found frequent references to difficulties controlling rumors regarding the safety and effectiveness of vaccine.

It was noted in the reports reviewed that responders should not be counted upon for information; rather agencies should communicate with one another to obtain information. Bharosa, Lee, and Janssen (2010) noted 
that relief workers are often more concerned with receiving information than passing information on to others. Jackson et al. (2006) noted that messages sent by responders need to be unified and clear and systems used to convey information needed to have interoperability. Baseman et al. (2013) described interoperable communications and real-time information sharing as paramount to protecting the public during an emergency response. The 2014 emergency communications plan specifically lists public health and medical among organizations that need to communicate and share information during emergencies, in addition to "traditional emergency responder disciplines" (3) and agencies overseeing public works and transportation. The plan notes that while some in agencies like public health and medical care may not be well-trained in areas of emergency communications, they can still play a valuable role in terms of surveillance and sharing information with the public using social media platforms and other technologies (National Emergency Communications Plan 2014).

The 2014 plan also calls for updating of standard operating procedures to ensure interoperable communications and timely information sharing with those in public health and the health care field. Representatives from such organizations should be included in the revisions of those procedures, with those new procedures including the contact information for key industry representatives to facilitate faster information sharing. Efforts to facilitate coordination in this area were regarded as important to the National Infrastructure Protection Plan, due to the fact that public health offices and hospitals may need to maintain a direct line of communication with emergency responders, and the Communications Act of 1934 defines as public safety agencies those whose "sole or principal purpose of which is to protect the safety of life, health, or property" (National Emergency Communications Plan 2014).

In regard to organizational difficulties with maintaining situational awareness, Militello et al. (2007) noted that simple communications can be distorted, creating confusion as to where resources should be sent. Fragmented information sharing caused some responders to become overloaded while others were underutilized. The core group of decision makers was left with less time to share information and delegate tasks. Outside of the core group people found it difficult to maintain enough situational awareness to identify areas in which they could help. Those who were able to overhear or deliberately sought information did find ways to help. Baseman et al. (2013) cautions that too much information sharing can create fatigue and harm responsiveness by limiting the ability to recall information. One strategy is to improve the consistency of health messages by reducing the level of redundancy, as research found that during the H1N1 pandemic in 2009-2010 health care providers became desensitized to information because of an excess of alerts. Hills et al. (2011) also note that information needs to be provided in an orderly manner to avoid alert fatigue.

On the issue of certain agencies not having access to information, Bharosa, Lee, and Janssen (2010) note that agency collaboration can be difficult even when agencies are occupying the same EOC during a response. Gebbie et al. (2006) note among their criteria for judging agency performance during an exercise the number of actions that help to facilitate all necessary agencies being included in the loop, including establishing a schedule to update partners regularly, testing backup communication procedures, and identifying a spokesperson appropriate to the emergency. The use of unidirectional communication can be counterproductive when trying to promote improved collaboration between responders. In a study by Revere et al. (2015), survey respondents reported wanting confirmation that messages sent had been received (as well as willingness to respond to messages sent) and also wanted to know how information sent had been utilized. There is substantial evidence from the literature that the quality and nature of information sharing in any type of emergency can have important implications for the citizenry. Those agencies tasked with maintaining safety and security during an emergency must receive accurate and consistent information, which is why some advocate for police, fire, and EMS sharing an EOC and that information manager positions be held by police officers (Bharosa et al. 2009).

Comfort et al. (2001) makes clear that technology is a crucial dimension in the sharing of coordinated information (as cited Bharosa, Lee, and Janssen 2010). Bharosa et al. (2009) describe the diversity of technology used by Dutch response agencies during exercises. Among these were the Flood Information and Warning System, used to optimize the sharing of information during dangerous high water situations within and between water management and emergency management organizations. Agencies also used ARCmap, a map-based GIS software, C2000 which is a communication system used by almost all relief agencies in the Netherlands and used for daily operations by the exercise participants, and MS Groove, CCS (Command and Control System) was employed for note taking, information clustering, and situation report communications. Another exercise employed CEDRIC, an extended email system for relief workers to generate, store, and edit situation reports as well GMS, a system to automatically document and assign incidents to first responders. Broadband technology has improved the ability to share information regarding patients during a pandemic response in real time, as sensors attached to a patient can transmit information regarding their vital signs to medical facilities, which could help the larger public health and medical community remain current with the severity of a pathogen's effects (National Emergency Communications Plan 2014). Revere et al. (2015) note that care must be taken when sharing potentially sensitive patient information so that violations of HIPAA are guarded against. 
Lubroth (2006) discusses the need, at the international level, for an alert and information exchange so that key international organizations can be kept appraised of the latest developments regarding threats to the international agricultural sector. As for the challenge of government agencies maintaining communications with the private sector during an emergency, Savoia, Agboola, and Biddinger (2012) found in their study of the response to H1N1 that establishing an effective channel of communication between government and the private sector represented a challenge.

Rao, Chaudhury, and Chakka (1995) noted that complexity is not just about the number of actors involved, but the interactions between different organizational levels within the network (as cited by Bharosa, Lee, and Janssen 2010). Poor information sharing can occur at the individual, community, or agency level (Bharosa, Lee, and Janssen 2010). Shared interpretation of information within and between agencies is also important. This can sometimes be complicated by the use of advanced software if not all involved are equally adept at using it and interpreting its outputs.

Lubroth (2006) noted that information important to determining the extent of an international biological threat to the agricultural system will be collected at the local level. Savoia, Agboola, and Biddinger (2012) noted that local public health agencies are important for communicating with the public, and should be more proactive in using the media for that purpose. Lubroth (2006) expressed concern that national health response plans did not adequately take into account international dimensions and noted that organizations like the Food and Agriculture Organization of the United Nations were concerned about the state of national, regional, and international response capabilities in the event of an emergency threatening agriculture.

\section{Limitations in the Literature}

The emergency management literature has limited systematic studies of after-action reports in general (see Knox 2013). There is also a lack of studies comparing different forms of prominent exercises related to health emergency preparedness. We need to not only make more effort to learn from these exercises individually, but we need to make more effort to learn from them as a body of knowledge as well.

\section{Significance for a Particular Audience}

This study will be of interest to scholars and practitioners in emergency management who may not be aware of some of these academic studies or high level exercises and could find value in relating the findings from these exercises to their preparedness work. The study may help to make connections between lower level considerations and more high-level discussions. The focus on preparedness issues such as communication and coordination for an infectious disease emergency is particularly relevant in light of the 2016 emergency preparedness rule from the Centers for Medicare and Medicaid Services, as well as on-going threats posed by measles, influenza, and Ebola. Finally, it provides policy recommendations which may prove useful in shaping information sharing for public health emergency preparedness moving forward.

\section{Purpose of the Study}

The purpose of the study is to closely examine strengths and vulnerabilities regarding information sharing based on preparedness exercises, as well as to determine their association with other key themes derived from those exercises' after-action reports. The information developed from the review of the exercises will be examined in light of the evolving National Emergency Communications Plan and existing literature to clarify improvements that have been made and areas specific to public health emergency preparedness that still need to be improved. One particular issue of concern is the manner in which public health information sharing can come into conflict with information sharing in areas like law enforcement during a deliberate biological attack. 


\section{Methodology}

\section{Data}

The goal of following study is to qualitatively identify key themes in after-action reports from preparedness exercises, compare those key themes to the existing literature, and, by synthesizing the two, develop recommendations for how exercises could be improved for the future. The author collected and reviewed the after-action exercises for two tabletop exercises, Dark Winter and Atlantic Storm. These documents were readily accessible using a Google search. An after-action report from an international functional exercise, Global Mercury, was also located via a Google search and reviewed. The after-action reports for four full-scale exercises, TOPOFF 1-4, were also collected from the Homeland Security Digital Library and other sites and reviewed. Notes were taken from each of these documents with a focus on challenges experienced during the exercise and lessons learned.

The webcast of the Clade X pandemic tabletop exercise conducted by the Johns Hopkins School of Public Health Center for Health Security on May 15, 2018 was viewed and extensive notes were taken. The project team for the exercise was led by Dr. Eric Toner and Dr. Crystal Watson. The exercise, which was broadcast via Facebook Live, presented a panel consisting of health experts, former legislators and officials, and current elected representatives with a scenario involving the release of an engineered biological weapons in the US and around the world. The exercise played out in four, approximately 90 minute segments, with each segment presenting participants with new aspects of the scenario to which they had to provide policy recommendations. The discussion was facilitated by Dr. Tom Inglesby, who played the role of the National Security Advisor. Participants similarly filled the roles of relevant Cabinet officers or administration officials (Johns Hopkins Bloomberg School of Public Health, 2018, May 15).

As this was a pandemic exercise conducted in real time and not an after-action report, attention was paid to policy problems experienced by the participants and challenges that the participants experienced resolving those problems. In regard to the reports, notes were taken to focus on the elements of interest in the reports, and filter out issues of planning, organization, and funding of the exercises which were not germane to the purpose of this research. The document containing the notes derived from the seven reports and the live exercise was 23 pages and 7252 words in length.

The approach to coding the qualitative data was based on the approach to grounded theory advanced by Glaser (1992) as described in McNabb (2008). This approach involved moving from an open coding approach to review what was substantively present in the data to theoretical coding to group the codes discovered in a meaningful way. The notes taken from the after-action reports listed in Table 1 were loaded into the QDA Miner software developed by Provalis Research. A content analysis was conducted using the associated Word Stat program to identify the most common words found in the notes taken from the reports. The top eight words the program identified in the notes, all with over 30 mentions, were: Information, Public, State, Federal, National, Response, Local, and Emergency. These words, as well as other less frequent terms, formed the basis of a coding scheme which was then applied to the document. This scheme consisted of five categories: Means, Behavior, Policies, Actors, and Context. Under each category were the following codes (see Table 2):

Table 1: Description of Exercise Scenarios.

\begin{tabular}{llll}
\hline Exercise Name & Year & Sponsor & Scenario \\
\hline TOPOFF 1 & 2000 & $\begin{array}{l}\text { Department of Justice/Federal } \\
\text { Emergency Management Agency }\end{array}$ & $\begin{array}{l}\text { Attacks involving a biological } \\
\text { weapon and a bombing using a } \\
\text { chemical agent on U.S. soil } \\
\text { Covert biological attack against }\end{array}$ \\
Dark Winter & $\begin{array}{l}\text { 2001(see O'Toole, } \\
\text { Michael, and } \\
\text { Inglesby 2002) }\end{array}$ & $\begin{array}{l}\text { Johns Hopkins Center for } \\
\text { Civilian Biodefense Strategies }\end{array}$ & $\begin{array}{l}\text { the U.S. using smallpox } \\
\text { TOPOFF 2 }\end{array}$ \\
2003 & $\begin{array}{l}\text { Department of Homeland } \\
\text { Security }\end{array}$ & $\begin{array}{l}\text { Attacks involving a radiological } \\
\text { (dirty) bomb and a biological }\end{array}$ \\
Global Mercury & 2003 & $\begin{array}{l}\text { Global Health Security Action } \\
\text { Group (led by Canada) }\end{array}$ & $\begin{array}{l}\text { Tested the ability to coordinate } \\
\text { an international response to a } \\
\text { terrorist attack using smallpox }\end{array}$
\end{tabular}




\begin{tabular}{|c|c|c|c|}
\hline TOPOFF 3 & $\begin{array}{l}2005 \text { (see } \\
\text { Department of } \\
\text { Homeland Security } \\
\text { Office of Inspector } \\
\text { General. November } \\
\text { 2005) }\end{array}$ & $\begin{array}{l}\text { Department of Homeland } \\
\text { Security }\end{array}$ & $\begin{array}{l}\text { Chemical attack in Connecticut } \\
\text { and a biological attack in New } \\
\text { Jersey }\end{array}$ \\
\hline Atlantic Storm & 2005 & $\begin{array}{l}\text { University of Pittsburgh Medical } \\
\text { Center, Center for Transatlantic } \\
\text { Relations at Johns Hopkins } \\
\text { University, and the Transatlantic } \\
\text { Biosecurity Network }\end{array}$ & $\begin{array}{l}\text { International biological attack } \\
\text { using the smallpox virus }\end{array}$ \\
\hline TOPOFF 4 & 2007 & $\begin{array}{l}\text { Department of Homeland } \\
\text { Security }\end{array}$ & $\begin{array}{l}\text { Radiological (dirty) bomb attacks } \\
\text { in Guam, Oregon, and Arizona }\end{array}$ \\
\hline Clade X & 2018 & $\begin{array}{l}\text { Center for Health Security at } \\
\text { Johns Hopkins University }\end{array}$ & $\begin{array}{l}\text { International release of a } \\
\text { genetically-modified } \\
\text { parainfluenza virus by a terrorist } \\
\text { group }\end{array}$ \\
\hline
\end{tabular}

Table 2: Categories and Codes Derived from After-Action Report and Exercise Notes.

\begin{tabular}{ll}
\hline Categories & Codes \\
\hline Means & Assets, Authority, Communication, Information, \\
& Personnel, Resources, Responders, Vaccine \\
Behavior & Sharing, Decisions \\
Policies & Quarantine, Travel Ban \\
Actors & Sector, Private, Countries, Agencies \\
Context & Federal, State, Local, International \\
\hline
\end{tabular}

\section{Results}

\section{Descriptive Analysis}

Sentences and phrases in the after-action report and exercise notes were then coded according to whether they corresponded with one or more of these codes (as defined in Table 2). The frequencies with which the different Means codes were applied in the notes is provided in Table 3 below:

Table 3: Coding Frequencies for the Means Category.

\begin{tabular}{lr}
\hline Category/Code & Frequency \\
\hline Means & 50 \\
Information & 34 \\
Communications & 19 \\
Resources & 18 \\
Personnel & 17 \\
Vaccine & 12 \\
Assets & 11 \\
Responders & 9 \\
Authority & 9 \\
\hline
\end{tabular}

Most of the codes were similarly represented in the notes, with the clear exceptions of Information and Communications. However, it should be noted that references to Information are present throughout a number of report notes while references to Communications are concentrated in notes for the exercise Global Mercury. This is logical as the primary purpose behind Global Mercury was to test the communication capacities of participating countries during an international health emergency. There was some consideration given to merging these two codes, however, they were left disaggregated because Information refers to material collected through 
processes such as surveillance, while Communication refers to the use of different modes of communication (email, teleconference, etc.).

The codes for the Behavior category, Sharing and Decisions, appeared 13 and 11 times in the notes, respectively. In the Policy category, Quarantine appeared 11 times and Travel Ban appeared 15 times. The frequencies for the codes in the Actors and Context categories appear below.

Frequencies speak to the fact that participation in the exercises was spread relatively equally between US government agencies (most notably federal and state), representatives of different countries, and the private sector. All of the exercises included participation by US government agencies, while most of the exercises, even those with a domestic focus, included some type of international component as well. The private sector is an important player to be considered in these exercises, even if they are not actively participating, because of the preeminent role they play in vaccine development. The fact that a public health emergency will play out at all levels of government and across continents is evident from the frequencies in Table 4 and Table 5 as well:

Table 4: Coding Frequencies for the Actors Category.

\begin{tabular}{lr}
\hline Agencies & 17 \\
Private & 15 \\
Countries & 14 \\
Sector & 11 \\
\hline
\end{tabular}

Table 5: Coding Frequencies for the Context Category.

\begin{tabular}{ll}
\hline State & 34 \\
Federal & 33 \\
Local & 27 \\
International & 24 \\
\hline
\end{tabular}

The TOPOFF exercises in particular focus on federal and state capabilities, while exercises like Atlantic Storm and Global Mercury were far more concerned with the international response. The Clade X exercise demonstrated how a pandemic that began in Germany could very quickly have consequences at the local level in the domestic US, as the exercise included an inject wherein a local health official quarantined a small local college. It should be noted that there was some concern on the part of the author because the after-action reports from the TOPOFF exercises were significantly longer and more detailed than those for the Dark Winter, Atlantic Storm, or Global Mercury exercises (as well as the notes taken for the Clade X exercise). While taking notes from the reports focusing specifically on challenges and lessons learned helped to address this disparity, there was still concern that the content of the TOPOFF reports may be overwhelming information from the four others. However, a review of the coding for only the four non-TOPOFF exercises found that Information was still a dominant theme with 22 occurrences (as opposed to 34 for communication and 23 for International).

\section{Correspondence Analysis}

As an additional check on the themes, the reports themselves were loaded into QDA Miner. The reports for TOPOFF 2 and TOPOFF 4 were not properly formatted for use with that program, so shorter summaries of the after-action reports for those exercises were used instead. The same coding scheme described above was used to code all relevant sentences in these documents. After that, a correspondence analysis was conducted using the coding frequencies. According to the QDA Miner manual, "[t]he correspondence analysis procedure implemented in QDA Miner allows you to graphically examine the relationship between assigned codes and subgroups of an independent variable" (QDA Miner 2006, 145). Specifically, the analysis was done to evaluate the degree to which distribution of codes were similar to one another within the documents and the degree to which the distribution of codes was similar to the distribution of all the codes within all the documents. Codes with similar distributions to one another will appear close to one another in the correspondence plot. Codes with similar distributions to all codes in all the documents will appear close to the origin point (QDA Miner 2006). 
The correspondence analysis plots the position of the codes on three different axes. When comparing each of these axes to one another, the code for Information appears close to the origin points. See the statistics in Table 6 below:

Table 6: Coordinates of Codes Based on Correspondence Analysis of AAR Codes.

\begin{tabular}{lrrr}
\hline Item & Axes 1 & Axes 2 & Axes 3 \\
\hline Information & -0.019 & -0.617 & 0.084 \\
Vaccine & -2.197 & 2.842 & -0.181 \\
Resources & -0.143 & 0.115 & 0.029 \\
Personnel & 0.526 & 0.109 & -0.408 \\
Assets & 0.660 & -0.008 & -1.658 \\
Responders & 0.745 & -0.306 & -3.019 \\
Authority & 0.713 & -0.050 & -1.029 \\
Communication & -0.511 & -1.936 & -0.583 \\
Sharing & 0.509 & -0.280 & 2.159 \\
Decisions & -1.306 & 2.016 & -0.342 \\
Quarantine & -1.385 & -0.830 \\
Travel Ban & -2.973 & 1.064 & 0.279 \\
Sector & 0.811 & 0.469 & 2.534 \\
Private & 0.763 & 0.062 & 2.215 \\
Countries & -2.398 & 0.062 & 0.197 \\
Agencies & 0.743 & -1.292 & -0.941 \\
Federal & 0.622 & -0.172 & -0.345 \\
State & 0.357 & 0.367 & 0.407 \\
Local & 0.625 & 0.755 & 0.193 \\
International & -2.012 & -0.302 & 0.241 \\
\hline
\end{tabular}

The statistics indicate that, taking all three axes into account, Information was, on average, second closest to the origin point after the code for Resources. This indicates that its distribution across the various reports was stable. This can also be seen in the correspondence plot in Figure 1 comparing Axes 2 and 3:

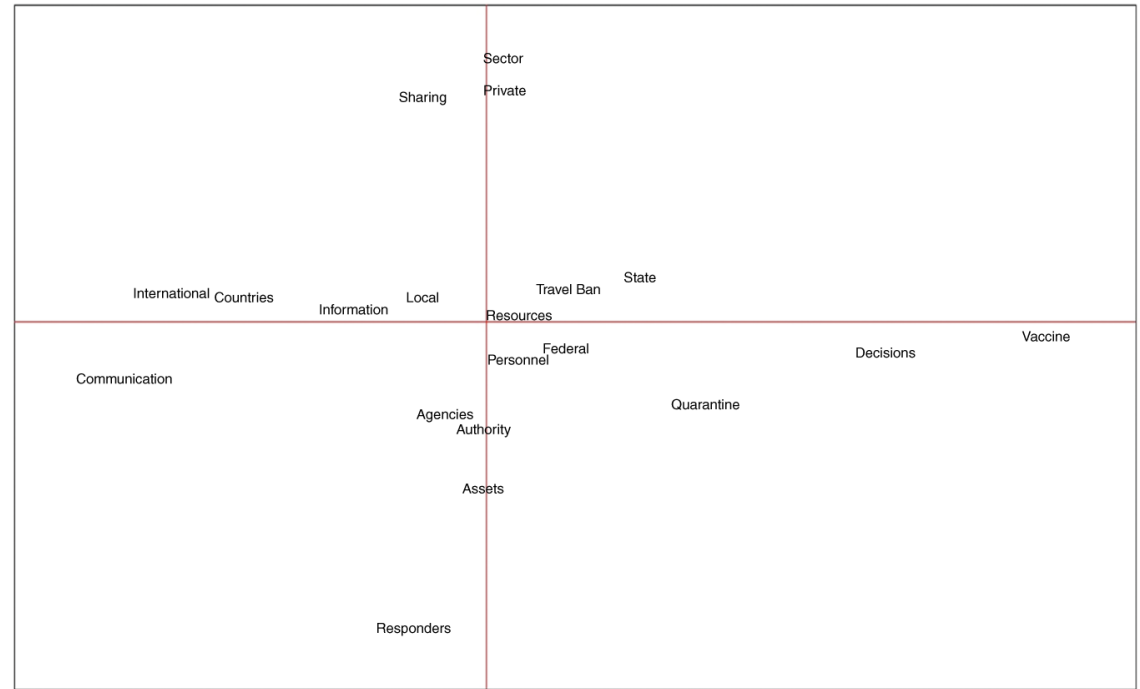

Figure 1: Correspondence Plot Comparing Coding on Axis 2 vs. the Coding on Axis 3.

In regard to interpreting the three axes, the codes that loaded most strongly on the first axis were the associated with the organizations that would be prominent in regard to preparing for or responding to an emergency and how to connect them. The code that loaded the strongest on that axis was sector, which speaks to the fact that the public and private sectors would need to coordinate and collaborate in the event of an emergency. The codes loaded most strongly on the second axis were those associated with the materials that would be needed to respond to an emergency, particularly one involving a public health threat. Vaccine was the code that loaded most strongly on this axis. Both the codes for Information and Sharing loaded most strongly on the third axis, along with codes associated with an international response (Countries and International). This speaks to the fact, as illustrated in the Global Mercury exercise, that information sharing will be particularly vital for managing an international response to a public health emergency. The code Private also loaded most strongly on 
this axis, speaking to the fact that more needs to be done to improve information sharing between the public and private sectors for emergency preparedness.

Despite the fact that this plot graphs the position of Information on the two axes where the code loaded the most differently, Information is still close to the origin point (the finding is more apparent in the other two plots). These findings provide additional quantitative evidence of the importance of Information in the discussions across the after-action reports. The themes of Resources, Communication, and State were also located consistently close to the origin point. Information Sharing is defined in the 2014 National Emergency Communication Plan as "the exchange of data, information, or knowledge between various organizations, people, and technologies" (3). This is differentiated from Communication for the purposes of this study, as Communication is defined as "internal and external mechanisms to maintain contact with stakeholders during an emergency," which in the case of this study often involves technological means (FEMA Glossary n.d.). Resources are also defined in the FEMA glossary as "major items of equipment, supplies, and facilities available or potentially available for assignment to incident operations and for which status is maintained (Federal Emergency Management Agency Glossary n.d.). State refers to state government agencies as stakeholders in an emergency response.

\section{Notable Passages from the Exercise Reports}

One area in which Information Sharing, Resources, Communication, and State (referring to state government) were connected in the after-action reports was the need to have personnel dedicated to communication. We often hear that more personnel are needed to help manage an emergency. However, one may tend to think of more personnel helping to manage operations on the front lines, as opposed to more individuals engaged in information management. However, it is argued in these after-action reports that in order to received needed information from the field, "[m]ore dedicated personnel for communications may need to be provided to address this" (TOPOFF 1 2001). Findings from the Global Mercury exercise (2003) note that organizational design and personnel training should be used as tools to promote "better collation, analysis, and interpretation of available information."

As discussed in the literature and the after-action reports, effective information sharing and communication between responders at the federal, state, and local level is imperative for maintaining situational awareness. The after-action report from TOPOFF 2 (2003) noted that information was delayed and that responders could find it difficult to separate facts from rumors. This type of uncertainty could have dire consequences during an actual response. Following TOPOFF 4 (2007), the AAR indicated that personnel had received information regarding the nature of a radiological threat through leaks as opposed to proper channels. This increases the possibility of decisions being made based on bad information. After the TOPOFF 4 (2007) exercise it was noted that personnel in the field should not be relied upon for intelligence during a response. Coordinating agencies should share information with one another and not place additional burdens on those on the front lines.

The performance of agencies and other actors in the field is determined in large part by the information they are able to receive. The AAR for TOPOFF 1 notes that all response agencies must be able to get accurate and timely information from the field (TOPOFF 12001 ). Without such information, agencies cannot determine priorities for allocating personnel and resources to manage the aftermath of the event. Agencies could, for example, find themselves trying to put out a real or proverbial fire that has already been extinguished. The TOPOFF 4 exercise (2006) highlighted a particularly serious example of this as it was noted in their after-action report that the Department of Homeland Security was delayed in providing information to the Department of Health and Human Services regarding how a nuclear detonation would affect the surrounding area.

A common reference to the use of information in an emergency response scenario is the contention from the Atlantic Storm report that information systems need to be built and improved to give leaders the situational awareness they need to make critical decisions (Smith et al. 2005). Executive level officials who have participated in tabletop pandemic exercises often note that in a real response scenario the amount and quality of information they received would not allow them to feel comfortable that they've made an informed choice. It was also noted in the AAR for the TOPOFF 3 (DHS Inspector General November 2005) exercise that a common information management system was needed to facilitate better decision making and improve accountability. This raises an important point, as it is difficult to blame government officials for not responding appropriately in an emergency if they lacked good information. Another issue of concern related to this category was the degree to which information was appropriately shared. For example, during TOPOFF 1, EPA representatives were not given access to Joint Operating Center (JOC) briefings, which hindered information-sharing early on. This improved as the exercise progressed (TOPOFF 12001 ). 
In addition to limited production and reporting of critical information in an emergency, problems can also stem from certain agencies not being adequately recognized as part of the response. Such findings are a strong argument for regular interagency exercises, as they should help to illustrate the importance of particular agencies under particular circumstances. One reason given for information not being shared in a timely manner was that doing so could jeopardize operational security by tipping off terrorists that the authorities were aware of their activities or tipping them off regarding how the authorities intended to respond. In the after-action-report for TOPOFF 4 (2006), it clearly states that operational security should only take precedence over information sharing in situations where the geographic location of an anticipated event is unknown and there is concern about an attack being triggered before adequate preparations can be made. An issue related to this, also noted after TOPOFF 4, was that classified and unclassified information were sometimes mixed, creating uncertainty about what could and could not be shared with the public.

The after-action report from TOPOFF 1 (2001) also called for the use of the most up-to-date technology to promote information sharing and situational awareness. It is worth noting that response agencies at the time that TOPOFF 1 took place had much less in terms of communication technology than we have today. The field of available technology is constantly evolving, and response agencies must attempt to stay current with these advancements. However, agencies must be prepared to employ such technology skillfully, or using it could create another set of problems. For example, the use of teleconferencing was recommended after the TOPOFF 1 exercise, but the after-action report from Global Mercury (2003) strongly suggested teleconferencing presented a considerable stumbling block to effective communication during the exercise. Following TOPOFF 4 (2006), lack of secure phones and computer systems were noted as a hindrance to sharing information.

In addition to problems associated with some important information not getting through, the after-action report from Global Mercury (2003) noted that information overload is a serious concern as well. Particularly important information must be carefully handled to avoid getting lost in the shuffle. It was also noted in that report that even with the large volumes of information it was difficult to get a full operational picture, and part of that difficulty may have come from the manner in which information was triaged. The same report notes that complexity of the communication system (i.e. employing too many modes of communication) can be a barrier to effective information sharing.

A particular issue regarding how timely and accurate information sharing is vital is changes to alert levels. The after-action report from the TOPOFF 1 exercise notes that different state and local governments and the private sector need to be in the loop regarding changes to alert levels (TOPOFF 1 2001). Otherwise confusion can occur regarding whether or not non-essential personnel should be dismissed early and allowed to evacuate. It was also noted in the AAR for TOPOFF 3 (DHS Inspector General November 2005) that the sharing of information with the private sector needs to be improved and that the private sector needs a better understanding of the actions federal officials take in response to different types of declarations. It was further noted that a lack of effective protocols for information sharing between government and the private sector harmed their ability to collaborate and coordinate with one another. This presents a significant concern as much critical infrastructure in the US is privately owned and the private sector is well-positioned to provide vital resources in an emergency that the government may be lacking. Background checks and costs may hinder the ability of some businesses to access government information sharing networks. However, the private sector has its own information sharing issues to address, as much of their communication is through ad-hoc associations, some members of which may have concerns about possible proprietary information sharing during an emergency. In the after-action report for TOPOFF 2, one of the issues for improvement was the creation of a procedure for how information regarding a change in alert level will be disseminated across different jurisdictions (TOPOFF 2 2003).

While providing accurate and timely information to response agencies is of the essence, making sure that all agencies are interpreting that information in the same way and conveying it to the public in a coordinated manner is also of importance. The importance of messaging being coordinated and accurately conveyed to all responses agencies and all segments of the public was noted in the AAR for TOPOFF 1 (TOPOFF 1 2001). The same after-action report makes clear that the roles of response agencies are to maintain order, preserve trust, and ease fears. If agencies are not coordinated in their sharing of information with the public, they will be likely to accomplish the exact opposite of these steps.

Another approach to keeping agency activities coordinated in the midst of a response, suggested after TOPOFF 4 (2006), was creating an interagency playbook with information relevant to all agencies during an emergency response. The idea of complexity within information networks is often associated with the number of agencies involved in those networks, but as Rao, Chaudhury, and Chakka (1995) note, the hierarchy of organizations involved in the response can be an issue as well.

It is clear from all of the after-action reports reviewed that a pandemic or any other type of large-scale response will involve all levels of the US government, and they need to be able to work in concert with one another. During the TOPOFF 2 exercise (2003), state and local officials reported feeling preempted by the federal gov- 
ernment in regard to the release of information. As noted above, if government responders are to preserve trust and order and alleviate public anxiety, communication with the public should be conducted in concert with one another. In the international arena, the AAR for Global Mercury (2003) made clear that the World Health Organization saw itself as a global leader for information collection and dissemination during an emergency. WHO saw significant gaps and duplication in the existing information network, contributing to disparities in the information available to participants when they needed to make decisions. Rather than numerous countries seeking information and advice from the first country reporting cases, the WHO volunteered itself as the hub for information collection and dissemination, allowing other countries to focus on treating and containing the threat. It was recommended at the conclusion of the report that the WHO Director review the organization's policies and priorities regarding information management. The European Commission made its own observations regarding the state of international response at the time of Global Mercury (2003), noting that the incident scale used to measure the severity of a threat needed to be refined and that it would be better for countries to share large amounts of data on web sites. The commission did note the value of countries exchanging information about their national response plans. However, these plans were found to vary in regard to quality, particularly in regard to the degree they took international issues into account.

\section{TOPOFF Exercises and the Nuclear Threat Initiative Report}

While it was conducted in 2003, the after-action report filed after the TOPOFF 2 exercise speaks to the issues of Information Sharing and its closely associated themes that still have relevance today, as noted in the recent tabletop exercise conducted by the Nuclear Threat Initiative (Cameron et al. 2019). The purpose of the TOPOFF 2 exercise was to test the capabilities of local, state, and federal officials, as well as some elements of the Canadian government, to respond to two simultaneous terrorist attacks: a radiological weapon in Seattle, WA and a biological weapon in the Chicago area.

In regard to providing timely and effective alerts, the response was found to be hindered by a lack of awareness of threat advisory systems, inconsistent or non-existent protocols for threat elevation notification, and a lack of clear language. Agencies at all levels of government were uncertain about what action they should take in response to a threat elevation, speaking to the need for greater synchronization between the federal, state, and local levels. The concerns about not being able to access resources due to the lack of a Stafford Act declaration remains very relevant in regard to public health emergencies today. Emergency responders continue to need better understanding of what is and is not available under the Stafford Act and the Public Health Act. Real-time data collection and sharing across the local, state, and federal levels, as well as between the public and private sectors, remains a challenge even with the continuing improvement in technology. Similar difficulties the report from the NTI tabletop (Cameron et al. 2019).

The findings from TOPOFF 2 found that better understanding of the limits and utility of predictive models was needed, and emergency responders today could still benefit from such training, particularly as it relates to infectious disease. The need for training when it comes to highly technical information continues today, although as noted by NTI, the need for technical understanding now extends to genetic samples, as control of a novel pathogen will hinge on the collection, sharing, and analysis of genetic data. In the case of genetic data, there are concerns not only about efficiently and effectively being able to share data, but willingness among actors to share data internationally, despite a recognized "duty to share" (Cameron et al. 2019).

The lack of an efficient and robust communication system in the health care sector at the time of TOPOFF 2 was identified as a weakness in the system as well. Today, interoperability and other issues continue to plague the health care sector, and the sharing of information between health care and public health remains a challenge. While the advent of electronic medical records has helped to mitigate dependence on phones and especially faxes, the communication between hospitals remains a challenge. Limitations when it comes to available resources and staff also remains a challenge. TOPOFF 4, which also involved a terrorism scenario, also raised questions about what information could be shared with the public without alerting terrorists to important information. In the findings from the NTI tabletop exercise, it was noted that there is a national tendency to conceal information collected by security services, and that involvement of law enforcement can hinder information sharing among law enforcement and health and humanitarian agencies because the law enforcement agencies could be perceived by some members of the public as more concerned with catching criminals than providing care (Cameron et al. 2019). Exercises in the U.S. have held to the principle that when it comes to information sharing, public health concerns should be emphasized over operational concerns (TOPOFF 4 2006). 


\section{Discussion}

Tabletop exercises such as Clade $\mathrm{X}$ and full-scale exercises like those conducted as part of the TOPOFF series can serve important functions in terms of raising awareness of the need for public health emergency preparations, promoting improved collaboration, and identifying areas of needed improvement in response agencies. One area of note in both the literature and the review of after-action reports with clear importance to both regular and extreme emergencies is the collection, analysis, and sharing of information. Amid concerns regarding the availability of vaccines and personal protective equipment, the need for social isolation measures, and the efficacy of limitations on travel and involuntary quarantines, the ability of response agencies to share information can easily be taken for granted. This may particularly be true in today's environment where advanced communications equipment is so ubiquitous. However, the after-action reports and literature review make clear that this is a subject in need of on-going attention at a policy and operational level.

Tabletop exercises tend to focus more on broader policy issues, but it is notable that lack of clarity regarding policy, particularly which agency or level of government has authority to take a particular action, was found to slow response during the TOPOFF exercises. Clearing up these on-going policy questions and making the answers readily available to responders in advance of an emergency could help to address a significant portion of the informational concerns, as well as addressing logistical issues seen in functional and full-scale exercises in advance.

More attention could be paid to these more logistical policy issues in future tabletop exercises which could help to improve performance during functional and full-scale exercises. In the future, it would be worth considering more often integrating tabletop and functional/full-scale exercises into larger, multi-day events. Hankins et al. (2012), as one example, discussed conducting functional exercises with rural hospital and other stakeholders and following it up with tabletop exercises later. Doing so in close succession would allow participants to see how policy proposals could play out in a response environment while also offering a chance for responders to identify policy issues mid-response which they could then refer to the tabletop participants for further discussion. Such a model could be especially useful for addressing issues of information collection, analysis, and dissemination. Tabletop participants may take for granted that responders will have access to certain information, while responders may lack appropriate context for why information is conveyed at a particular point using a particular method. Allowing participants of these different types of exercises to more often share information with each other concomitantly could be a positive step toward promoting better information management during the next public health emergency.

Other recommendations for improving preparedness for future emergencies based on the findings above would include providing more education on emergency declarations and the laws governing response during a public health emergency. Information from the TOPOFF exercises indicates that communicating changes to alert levels can hinder a response through the misallocation of resources. Officials responsible for a public health emergency response effort must also be knowledgeable about which laws they can seek assistance under and which they cannot. Again, attempting to seek aid under an inapplicable statute or waiting for aid to be provided under an inapplicable statute will result in a misallocation of resources and wasting valuable time.

Public health labs should be better integrated into preparedness exercises in a number of ways. First, in regard to the problem of predictive models, epidemiologists and laboratory staff can be employed during tabletop exercises to educate other responders about the strengths and limitations of predictive models so they have a better sense of the parameters within which decisions should be made based on those models. Additionally, with the new prominence of genetic data in an infectious disease response, public health laboratories should partner with hospitals and other health care facilities on functional exercises regarding secure data sharing of genetic data involving a virus, as well as the analysis of such samples.

Also on the topic of information sharing, bi-directional information sharing between public health departments and hospitals needs to be routinized. Part of this could involve strengthening existing surveillance systems in the manner of a "bow-tie" architecture (see Comfort 2007) so that hospitals are regularly communicating syndromic surveillance data to state health departments who then communicate it to local health departments and any other relevant responders for potential action.

If a situation changes from a surveillance situation to a response, it may be necessary to employ the starburst approach discussed in the Global Mercury (2003) report. Hospitals would continue to provide information to the state department of health, and the state would continue to transmit information to local health departments, as before. Then local health departments would communicate updates about their situation back to the state, who then disseminate it to other local health departments in the state, who would then communicate the information to health care facilities in their jurisdiction. The Incident Command System should be activated and the Liaison Officer, along with others in the ICS staff with information sharing responsibilities, should be tasked with making sure the information sharing system remains functional in real time without overloading health care facilities or public health departments with information or responsibilities. 
Effort should continue to be made to fully realize the recommendations of the Joint Advisory Committee on Communications Capabilities of Emergency Medical and Public Health Care Facilities (2008), which advocated for Internet Protocol-based communication systems that would converge voice and data and thus create more efficient communications (8). While significant progress has been made on a number of the committee's primary recommendations (for example, expansion of the practice of telemedicine), significant segments of the U.S. are still lacking in terms of broadband Internet capability, and, as noted previously, inoperable communications between hospitals and others in the health care system remains an issue. This committee should be reestablished and its work revisited in order to promote improvements in advance of a major public health emergency. The National Emergency Communication Plan should also be revised with additional consideration given to public health emergencies. A 2018 biennial progress report on emergency communications noted that, in regard to interoperability, that 48 out of 56 states and territories covered broadband access as part of their interoperability plan, however mobile coverage interoperability and coverage gaps remain areas of national concern (Cybersecurity and Infrastructure Security Agency 2019, ii). In the same report, it was noted that $95 \%$ of agencies surveyed had personnel trained in communications. While $74 \%$ of those surveyed indicated participation in exercises, only $41 \%$ reported evaluating and documenting the results of exercises. Almost half of those responding to the survey expressed the opinion that exercises were insufficient in terms of addressing interoperability and continuity during unplanned events (Cybersecurity and Infrastructure Security Agency 2019, iii).

Finally, increased trust should be promoted between those who would be tasked with investigating a bioterrorism attack as a criminal matter and those charged with addressing it as a medical emergency. Tabletops and functional exercises specifically addressing a bioterrorism scenario should be held with criminal investigators actively participating. This would allow investigators to share with health responders what access they would need to find the perpetrators, and allow the responders to share what limitations they may experience in terms of providing certain information. Addressing these issues in a tabletop format will allow individuals coming at an incident with very different perspectives and backgrounds to discuss any cultural, philosophical, or practical challenges they may have cooperating together before they become obstacles to treating members of the public or preventing future attacks. This could involve agreements on law enforcement delaying certain actions (such as making arrests or bringing certain people in for questioning) until such time as they would not hinder the active treatment of the ill. On the other hand, it could also involve public health responders being prepared to take note of things that could be actionable by law enforcement and being willing to report them at the appropriate time. Such arrangements will require compromises on both sides, but it is best that those compromises are agreed upon in advance.

\section{Conclusion}

Preparedness exercises from the original TOPOFF exercise to the Nuclear Threat Initiative tabletop exercise held in 2019 highlight the importance of information sharing to an effective response. This was supported by a review of reports filed after each exercises and a correspondence analysis of the results of that review. Technological capacity in the area of communication is regularly advancing in the United States. However, it is important to note that these advancements are not shared uniformly, as there are many parts of the country still lagging behind in regard to broadband access. Furthermore, usefulness of technological capacity can be stymied if systems are not compatible. This is why interoperability continues to be a serious focus of discussion in the medical community.

Just as important as interoperability between communication platforms is interoperability between levels of government and between government and the non-profit and private sectors. When levels of government fail to communicate with each other effectively on issues like changing the status of an emergency alert or the lack of communication protocols with the private sector, it can be more detrimental to a response than equipment failure. This is why the relationship building aspect of preparedness exercises should not be overlooked or taken for granted. The more opportunities that are available for agencies or organizations to learn about each other's protocols and procedures and to build a sense of professional trust, the more durable the system will be when placed under stress during an emergency.

Finally, policies must be consistently reexamined, from the local to the federal level. Of particular note are policies to increase interoperability and access to broadband networks, which have been in progress for over a decade. Also, the National Emergency Communication Plan needs further revision to better address the unique information sharing challenges involved a public health emergency. Private sector hospitals and health care facilities need to be more mindful of interoperability when making decisions about their own communication 
networks. We should not wait for the after-action report from a real biological attack to make these changes which have long been seen as necessary.

\section{Acknowledgments}

The author wishes to acknowledge the assistance of Jason Collins in collecting, organizing and summarizing information that was necessary for the completion of this manuscript.

\section{References}

Annas, Ceorge. 2002. "Bioterrorism, Public Health, and Civil Liberties." New England Journal of Medicine 346(17): 1337-1342.

Baseman, Janet G., Debra Rever, lan Painter, Mariko Toyoji, Hanne Thiede, and Jeffrey Duchin. 2013. "Public Health Communication and Alert Fatigue". BMC Health Services Research 13(1): 295.

Bharosa, Nitesh, JinKyu Lee, and Marjin Janssen. 2010. "Challenges and Obstacles in Sharing and Coordinating Information During MultiAgency Disaster Response: Propositions from Field Exercises." Information Systems Frontiers 12: 49-65.

Bharosa, Nitesh, JinKyu Lee, Marjin Janssen, and H. Raghav Rao. 2009. "A Case Study of Information Flows in Multi-agency Emergency Response Exercises." The Proceedings of the 10th International Digital Covernment Research Conference, 277-282. Digital Covernment Society of America. Accessed from https://www.researchgate.net/profile/Nitesh_Bharosa/publication/221584629_A_case_study_of_information_flows_in_multiagency_emergency_response_exercise/links/54fdc7e30cf20700c5ecoe58.pdf on January 7, 2020.

Biddinger, Paul, Elena Savoia, Sarah Massin-Short, Jessica Preston, and Michael Stoto. 2010. “Public Health Emergency Preparedness Exercises: Lessons Learned." Public Health Reports 125(Supplemental 5): 100-106.

Cameron, Elizabeth, Rebecca Katz, Jeremy Konyndyk, and Michelle Nalabandian. 2019, June 13. "A Spreading Plague: Lessons and Recommendations for Responding to a Deliberate Biological Event." Nuclear Threat Initiative. Accessed from https://www.nti.org/analysis/reports/spreading-plague-lessons-and-recommendations-responding-deliberate-biological-event/ on July 31, 2019.

Comfort, Louise K., Yesim Sungu, David Johnson, and Mark Dunn. 2001. “Complex Systems in Crisis: Anticipation and Resilience in Dynamic Environments." Journal of Contingencies and Crisis Management 9(3): 144-158.

Comfort, Louise K. 2007. "Crisis Management in Hindsight: Cognition, Communication, Coordination, and Control." Public Administration Review 67: 189-197. https://doi.org/10.1111/j.1540-6210.2007.00827.x.

Cybersecurity and Infrastructure Security Agency, U.S. Department of Homeland Security. February 2019. "Biennial Progress Report on Emergency Communications: Report to Congress for Fiscal Years 2016-2018." Accessed from https://www.dhs.gov/sites/default/files/publications/biennial_progress_report_on_emergency_communications_fy16fy18_02152019_final_508_0.pdf on August 6, 2019.

Dausey, David, James Buehler, and Nicole Lurie. 2007. “Designing and Conducting Tabletop Exercises to Assess Public Health Preparedness for Manmade and Naturally Occurring Biological Threats." BMC Public Health 7: 92-101.

Department of Homeland Security Office of Inspector General. November 2005. "A Review of the Top Officials 3 Exercise." Accessed from https://www.oig.dhs.gov/assets/Mgmt/OIC_06-07_Nov05.pdf on July 31, 2018.

Endsley, M. R., and D. J. Garland. 2000. Situation Awareness Analysis and Measurement. Mahwah: Lawrence Erlbaum Associates.

Exercise TOPOFF 2000 and National Capital Region (NCR) After Action Report. August 2001. The National Response Team. Accessed from https://www.nrt.org/sites/2/files/TOPOFF.pdf on July 31, 2018.

Federal Emergency Management Agency. No Date. “Clossary.” Accessed from https://training.fema.gov/programs/emischool/el361toolkit/glossary.htm on August 7, 2019.

Cebbie, Kristine, Joan Valas, Jacqueline Merrill, and Stephen Morse. 2006. “Role of Exercises and Drills in the Evaluation of Public Health in Emergency Response." Prehospital and Disaster Medicine 21(3): 173-182.

Glaser, Barney. 1992. Emerging vs. Forcing: Basics of Crounded Theory Analysis. Mill Valley, CA: Sociology Press.

"Clobal Mercury Post-Exercise Report." 2003. Accessed from https://www.rki.de/EN/Content/infections/biological/Preparedness_Plan/Exercise. pdf? _blob=publicationFile on July 31, 2018.

Hankins, David, Marti Burns, Pat Kuhlman, Tim Baldwin, Jennifer Smock, Andrew Bynum, Julie E. Shaffner, J. Eric Dietz, and David Black. 2012. In “Chapter13-Lessons Learned from Tabletop Exercises" from Pandemic Planning, edited by ]. Eric Dietz and David Black. New York: CRC Press.

Hills, Rebecca A., Janet G. Baseman, Debra Revere, Craig L. K. Boge, Mark W. Oberle, Jason N. Doctor, and William B. Lober. 2011. "Applying the XForms Standard to Public Health Case Reporting and Alerting." Online Journal of Public Health Informatics 3(2). DOI: 10.5210/0jphi.v3i2.3656.

Jackson, Brian, Jame Buehler, Dana Cole, Susan Cookson, David Dausey, Lauren Honess-Moreale, Susan Lance, Roger Molander, Patrick O’Neal, and Nicole Lurie. 2006. "Bioterrorism with Zoonotic Disease: Public Health Preparedness Lessons from a Multiagency Exercise." Biosecurity and Bioterrorism: Biodefense Strategy, Practice, and Science 4(3): 287-292.

Johns Hopkins Bloomberg School of Public Health Center for Health Security. 2018, May 15. “Clade X-A Pandemic Exercise." Accessed from http://www.centerforhealthsecurity.org/our-work/events/2018_clade_x_exercise/index.html on July 31, 2018.

Joint Advisory Committee on Communications Capabilities of Emergency Medical and Public Health Care Facilities. 2008, February 4. Report to Congress. Accessed from https://www.ems.gov/pdf/FCC-JAC-Report.pdf on August 6, 2019. 
Knox, Claire Connolly. 2013. “Analyzing After-Action Reports from Hurricanes Andrew and Katrina: Repeated, Modified, and Newly Created Recommendations." Journal of Emergency Management 11(2): 160-168.

Lubroth, J., 2006. "International Cooperation and Preparedness in Responding to Accidental or Deliberate Biological Disasters: Lessons and Future Directions." Revue Scientifique et Technique-Office International des Epizooties 25(1): 361.

Lurie, Nicole, Jeffrey Wasserman, and Christopher Nelson. 2006. "Public Health Preparedness: Evolution or Revolution?" Health Affairs 25(4): 935-945.

McNabb, David. 2008. Research Methods in Public Administration and Nonprofit Management. 2nd ed. Armonk, NY: M.E. Sharpe.

Militello, Laura, Emily Patterson, Lynn Bowman, and Robert Wears. 2007. "Information Flow During Crisis Management: Challenges to Coordination in the Emergency Operations Center." Cognition Technology \& Work 9: 25-31.

National Emergency Communications Plan. July 2008. Department of Homeland Security. Accessed from https://www.hsdl.org/?view\&did=487839 on July 31, 2019.

National Emergency Communications Plan. 2014. Department of Homeland Security. Accessed from https://www.dhs.gov/sites/default/files/publications/2014\%20National\%20Emergency\%20Communications\%20Plan_October\%2029\% 202014.pdf on July 31, 2019.

No Author. “Emergency Preparedness Rule.” Centers for Medicare and Medicaid Services. January 20, 2017. https://www.cms.gov/Medicare/Provider-Enrollment-and-Certification/SurveyCertEmergPrep/Emergency-Prep-Rule.html (accessed February 2, 2017)

O’Toole, Tara, Mair Michael, and Thomas V. Inglesby. 2002. "Shining Light on “Dark Winter"." Clinical Infectious Diseases 34(7): 972-983.

Peterson, Danny and Ronald Perry. 1999. "The Impacts of Disaster Exercises on Participants." Disaster Prevention and Management 8(4): 241254.

Rao, H. Raghav, Abhijit Chaudhury, and M. Chakka. 1995. “Modeling Team Processes: Issues and a Specific Example." Information Systems Research 6(3): 255-285.

Revere, Debra, Kailey Nelson, Hanne Thiede, Jeffrey Duchin, Andy Stergachis, and Janet Baseman. 2011. "Public Health Emergency Preparedness and Response Communications with Health Care Providers: A Literature Review." BMC Public Health 11(1): 337.

Revere, Debra, Rebecca Calhoun, Janet Baseman, and Mark Oberle. 2015. “Exploring Bi-Directional and SMS Messaging for Communications Between Public Health Agencies and Their Stakeholders: A Qualitative Study". BMC Public Health 15: 1-13.

Salas, E., and S. M. Fiore. 2004. Team Cognition: Understanding the Factors that Drive Process and Performance. Washington: American Psychological Association.

Savoia, Elena, Folusa Agboola, and Paul Biddinger. 2012. “Use of After-Action Reports (AAR's) to Promote Organizational and Systems Learning in Emergency Preparedness." International Journal of Environmental Research and Public Health 9: 2949-2963.

Skryabina, Elena, Gabriel Reedy, Richard Amlot, Peter Jaye, and Paul Riley. 2017. "What is the Value of Health Emergency Preparedness Exercises? A Scoping Review Study." International Journal of Disaster Risk Reduction 21: 274-283.

Smith, Bradley T., Thomas V. Inglesby, Esther Brimmer, Luciana Borio, Crystal Franco, Gigi Kwik Gronvall, Bradley Kramer, Beth Maldin, Jennifer Nuzzo, Ari Schuler, Scott Stern, Donald A. Henderson, Randall ]. Larsen, Daniel S. Hamilton, Tara O’Toole. 2005. “Navigating the Storm: Report and Recommendations from the Atlantic Storm Exercise." Biosecurity and Bioterrorism: Biodefense Strategy, Practice, and Science 3(3): 256-267.

"T4 Command Post Exercise After Action Report." 2006, June 19-21. Accessed from https://archive.org/stream/TOPOFF4AfterActionReport/ 2017-FEFO-01031\%20Responsive\%20Records\%20-\%20TOPOFF\%204\%20AAR djvu.txt on July 31, 2018.

Top Officials 4 Full Scale Exercise After Action Quick Look Report. 2007, November 19. Accessed from https://www.hsdl.org/?view\&did=486802 on July 31, 2018.

TOPOFF 2 (T2) After Action Report. 2003, September 30. Accessed from https://www.hsdl.org/c/.

TOPOFF 2 National Response Team Lessons Learned Report After Action Review: Issues, Discussion, and Recommendation. The National Response Team. 2003. Accessed from https://www.nrt.org/sites/2/files/Final\%20TOPOFF2\%20Lessons\% 20Learned\%20Document\%202.pdf on July 31, 2018.

Verni, Christina. 2012. "A Hospital System's Response to a Hurricane Offers Lessons, Including the Need for Mandatory Interfacility Drills." Health Affairs 31(8): 1814-1821.

Walker, Denise. 2011. Mass Notification and Crisis Communications: Planning, Preparedness, and Systems. Boca Raton, FL: Chapman and Hall/CRC. World Health Organization. February 2017. “WHO Simulation Exercise Manual.” Accessed from https://apps.who.int/iris/bitstream/handle/10665/254741/WHO-WHE-CPI-2017.10-eng.pdf?sequence=1 on June 27, 2019.

Zylberman, Patrick. 2010. “Neither Certitude Nor Peace: How Worst-Case Scenarios Reframed Microbial Threats, 1989-2006." MCIS Briefings. Accessed from https://www.researchgate.net/profile/Regine_King/publication/254941212_Healing_Psychosocial_Trauma_in_the_Midst_of_ Truth_Commissions_The_Case_of_Gacaca_in_Post-Cenocide_Rwanda/links/55677ab808aeab77721ea98d/Healing-PsychosocialTrauma-in-the-Midst-of-Truth-Commissions-The-Case-of-Cacaca-in-Post-Cenocide-Rwanda.pdf\#page=15 on June 23, 2018. 